\title{
The 5-8-Day Kelvin and Rossby Waves in the Tropics as Revealed by Ground and Satellite-Based Observations
}

\author{
S. SRIDHARAN \\ National Atmospheric Research Laboratory, Gadanki, India \\ T. TSUDA, T. NAKAMURA, and T. HORINOUCHI \\ Research Institute for Sustainable Humanosphere, Kyoto University, Uji, Japan \\ (Manuscript received 29 January 2007, in final form 21 September 2007)
}

\begin{abstract}
An eastward propagating Kelvin wave of period near 7 days is observed in the radiosonde winds and temperature in the upper troposphere and lower stratosphere (UTLS) region and a wave of similar periodicity is observed simultaneously in the Mesosphere and Lower Thermosphere (MLT) winds acquired by $\mathrm{MF}$ radar at Pameungpeuk $\left(7.5^{\circ} \mathrm{S}, 107.5^{\circ} \mathrm{E}\right)$ during the first Coupling Processes in the Equatorial Atmosphere (CPEA-1) Campaign (April 10-May 9, 2004). The horizontal and vertical characteristics of these waves are investigated using winds and temperature data acquired by TIDI (TIMED Doppler Interferometer) and Sounding of Atmosphere using Broadband Emission Radiometry (SABER) instruments respectively on TIMED (Thermosphere Ionosphere Mesosphere Energetics and Dynamics) satellite and European Centre for Medium-Range Weather Forecasts (ECMWF) winds and temperature. The wave observed in the MLT region has a dominant period of approximately 6.5 days and is found to propagate westward with zonal wave number 1 . The horizontal structures of the wave in winds and the temperature indicate that the wave is of gravest symmetric wave number 1 Rossby wave. The downward phase propagation from the MLT region to tropopause indicates that the wave may have a source in the troposphere. The Kelvin wave observed in the UTLS region has zonal wave number 3. However, this wave becomes damped above $23 \mathrm{~km}$, where the above mentioned westward propagating wave begins to amplify. During the observation period, the OLR distribution in the tropics shows similar periodicities, propagating eastward with zonal wave number 3 and westward with zonal wave number 1 . These observations suggest that tropical convective heating may be a common source for these waves.
\end{abstract}

\section{Introduction}

Atmospheric theory suggests the existence of a free oscillation (normal mode) having a period of five days with asymmetric meridional structure and zonal wave number 1 (Longuet-Higgins 1967). Mesosphere and lower thermosphere (MLT) ob-

Corresponding author: S. Sridharan, National Atmospheric Research Laboratory, P.O. \& Vill. Gadanki, Pakala Mandal-517 112, Chitoor District, Andhra Pradesh, India.

E-mail: susridharan@narl.gov.in

(C)2008, Meteorological Society of Japan servations indicate the presence of a wave having a longer period of approximately 6.5 days during equinox months, the characteristics of which are consistent with those of the 5-day wave, which has led to the wave being considered as a 'Dopplershifted 5-day wave' (Wu et al. 1994). However, since the wave shows phase variation with altitude, its characteristics differ from the normal mode. In addition, according to Meyer and Forbes (1997), the change of 5-day wave period due to Doppler shift would be less than 0.5 days. They suggested that baroclinic instability in the mid-latitude mesosphere could generate planetary waves and were 
able to identify a peak near 6.5 days using the Global Scale Wave Model (GSWM) as a response of the westward zonal wave number 1 to the mesospheric in situ momentum source. This theory is supported by the High Resolution Doppler Imager (HRDI) observational analysis of Lieberman et al. (2003). Alternatively, using HRDI observations of winds, temperature and atomic oxygen, Talaat et al. (2001) reported a different picture of the 6.5-day wave as an internal, forced oscillation, propagating from the lower atmosphere and having an amplitude growth rate that exceeds that of normal modes below $80 \mathrm{~km}$. Using both HRDI and United Kingdom Meteorological Office (UKMO) data, Talaat et al. (2002) further extended the study and found that the wave appeared to grow from the stratosphere and continuously propagated into lower thermosphere.

Our previous observational study using intensive radiosonde wind and temperature measurements over Indonesia during the Coupling Processes in the Equatorial Atmosphere (CPEA-I) radiosonde observation campaign (April 10May 9, 2004) revealed the presence of a 7-day Kelvin wave in the upper troposphere and lower stratospheric (UTLS) region. Together with the analysis of Sounding of Atmosphere by Broadband Emission Radiometry (SABER) temperature data, the wave has been identified as an eastward propagating Kelvin wave with zonal wave number 3 (Sridharan et al. 2006a). However, the wave appeared to be damped above $23 \mathrm{~km}$. An analysis of simultaneous MF radar zonal wind data over Pameungpeuk $\left(7.5^{\circ} \mathrm{S}, 107.5^{\circ} \mathrm{E}\right)$, Indonesia showed a wave of similar period ( $\sim 6.5$-days) in the MLT region (Sridharan et al. 2006b). Unfortunately, during CPEA-1, the MLT wind data were available at the Pameungpeuk site only, and so we were unable to identify the zonal propagation characteristics of the wave and whether there existed any relationship between the two waves of nearly similar periodicities that appeared in the UTLS and MLT regions. In the present study, which can be considered as an extension of these previous studies, we investigate the horizontal and vertical structures of these waves during March-May 2004 from the troposphere to the MLT region using temperature and wind data acquired, respectively, by SABER and TIMED Doppler Interferometer (TIDI) instruments aboard the Thermosphere Ionosphere Mesosphere Energetics and Dynamics (TIMED) satellite and European Centre for Medi- um Range Weather Forecasting (ECMWF) winds and temperature data. As these global data sets of horizontal winds and temperature collectively cover most of the altitudes from the troposphere to the MLT region, they provide an opportunity to examine both the horizontal and vertical structures of the waves from the troposphere to the MLT region. In addition, we investigate the generating mechanisms of these waves.

\section{Data analysis}

\subsection{MF radar data}

The MF radar at Pameungpeuk has been operating at a frequency of $2.008 \mathrm{MHz}$ with a peak power of $30 \mathrm{~kW}$ since March 24, 2004. The antenna array, consisting of three antennas arranged in an equilateral triangle, is used for both transmission and reception. Using the spaced antenna method, the radar estimates horizontal winds from 52 to $98 \mathrm{~km}$ with a sampling rate of approximately 1.5 minutes. The data acceptance rate is high in the altitude region 80 to $98 \mathrm{~km}$, with the highest data rate at around $90 \mathrm{~km}$. The data for the CPEA-I radiosonde observation period (April 10May 9, 2004) are used in the present study.

\subsection{TIMED-SABER temperature data}

The temperature data at altitudes of from 15 to $100 \mathrm{~km}$ and horizontal wind data at altitudes of from 80 to $110 \mathrm{~km}$ obtained, respectively, from the SABER and TIDI instruments aboard the TIMED satellite are also used to obtain the vertical propagation of the wave from the troposphere to the MLT region. The SABER can be described briefly as a 10-channel broad-band limb-viewing, infrared radiometer that has been measuring stratospheric and mesospheric temperatures, mainly from the $15-\mu \mathrm{m}$ radiation of $\mathrm{CO}_{2}$, since the launch of the TIMED satellite. The data retrieval methods and their validation are described in Ramsberg et al. (2003). The TIDI is basically a Fabry-Perot interferometer with a CCD detector, which primarily measures horizontal vector winds from the Earth's limb, with a vertical resolution of $2.5 \mathrm{~km}$ and an accuracy that approaches approximately $3 \mathrm{~m} \mathrm{~s}^{-1}$ under optimum viewing conditions. The TIDI design allows for $100 \%$ duty cycle instrument operation during daytime, nighttime, and in auroral conditions. TIDI views emissions from OI 557.7 $\mathrm{nm}$ and $\mathrm{O}_{2}(0-0)$ to determine Doppler wind. An overview of the TIDI Doppler Interferometer can be found in Killeen et al. (2006). 


\subsection{ECMWF data}

In the present paper, we use ERA-40 winds (zonal and meridional) and temperature data for the pressure levels from the surface to $1 \mathrm{hPa}$. These reanalysis data are a new synthesis of in-situ and remotely sensed measurements for the period since mid 1957. These data were prepared by the European Center for Medium Range Weather Forecasting (ECMWF) using their variational data assimilation system. The ERA-40 data set consists of analyses conducted at six-hour intervals since 1957. These data are available for a $2.5^{\circ}$ latitudelongitude grid and for 23 standard pressure levels from the surface to $1 \mathrm{hPa}$. More details about the ERA-40 data can be obtained from the ECMWF website (http://www.ecmwf.int/research/era).

The satellite data were first binned for each 10 $\circ$ of latitude and for every $30^{\circ}$-interval of longitude $\left(0^{\circ}-30^{\circ} \mathrm{E}, 30^{\circ}-60^{\circ} \mathrm{E}\right.$, etc.). For each day, a zonal wave number spectrum is extracted and the individual zonal wave number spectrum for the period of March 23-May 26, 2004, which includes the CPEA-1 radiosonde campaign (April 10-May 9, 2004), is again Fourier analyzed in order to obtain the amplitude and phase for each zonal wave number-frequency component. The amplitude corresponding to the dominant period of the wave is used to represent the wave amplitude at each altitude and zonal wave number, and the phase of the wave corresponding to the longitude of $15^{\circ} \mathrm{E}$ is taken.

\subsection{OLR data}

Interpolated daily Outgoing Longwave Radiation (OLR) data obtained since June 1974 by NOAA satellite are available from the NOAA website for the $2.5^{\circ}$ latitude-longitude grid. In the present study, the OLR data for the period from March to May 2004 are used as a proxy for tropical convection and to determine the period and horizontal structure of the convectively generated waves. A description of a complete (interpolated) outgoing longwave radiation dataset was given by Liebmann and Smith (1996).

\section{Results}

\subsection{Zonal character in the MLT region}

To find the zonal propagating characteristics of the 5-8-day wave in the mesosphere and the lower thermosphere, we apply a 5-8-day band-pass filter to the TIDI zonal winds, which are averaged for latitudes from $5^{\circ} \mathrm{N}$ to $5^{\circ} \mathrm{S}$ at $90 \mathrm{~km}$ for the period from March to May 2004. Figure 1 shows the longitude-time cross section of 5-8-day filtered winds over the equator and for the period from March to May 2004. The filtered winds show larger amplitudes (approximately $40 \mathrm{~m} \mathrm{~s}^{-1}$ ) during days 90 through 120 (April 2004), although the wave persists, with relatively smaller amplitudes during May 2004. The wave has larger amplitudes at all longitudes, indicating that the observed wave is a planetary-scale wave. In particular, the wave is more active in the longitude band from $100^{\circ}$ to $180^{\circ} \mathrm{E}$. From the westward tilting of phase along the longitude, we can infer that the wave propagates westward. The wave takes nearly five days to propagate around the globe, which indicates that the wave has zonal wave number 1 .

\subsection{Altitude structure in the $M L T$ region}

Next, we describe the altitude structure of the 5-8-day wave in the TIDI winds and MF radar winds. In the left panel of Fig. 2, the dominant period of the wave computed from the zonal wind data acquired by the Pameungpeuk MF radar is plotted (dash-dotted curve) as a function of altitude. In order to find the dominant period of the wave, periodogram analysis is adopted. The hourly zonal wind data is fitted with the sinusoidal curve of period changing systematically from 120 to 192 hours in steps of 0.5 hours, and the period of the wave is taken to correspond to the fitted curve, which produced maximum response. Although the period of the wave varies slightly with altitude, it is found to be around 6.5-days in height, where the amplitude of the wave is maximum. Hereinafter, the wave observed in the MLT region will be referred to as the 6.5-day wave. Hence, the amplitude and phase of the wave corresponding to the period of 6.5 days is plotted as a function of altitude. The wave amplitude and relative phases of the W1 (solid curve) and E1 (dashed curve) components of the 6.5-day wave in TIDI zonal winds over the equatorial region $\left(5^{\circ} \mathrm{S}-5^{\circ} \mathrm{N}\right)$ are plotted for altitudes from 80 to $110 \mathrm{~km}$ for comparison. W1 refers to the westward propagating wave with zonal wave number 1 , and E1 refers to the eastward propagating wave with zonal wave number 1. In TIDI wind amplitudes, the W1 component is more dominant at all heights, as compared to the E1 component. The altitude structure of the W1 component is similar to that of the 6.5-day wave in the MF radar winds, although there is a difference in the values. The 5-8-day wave amplitude 


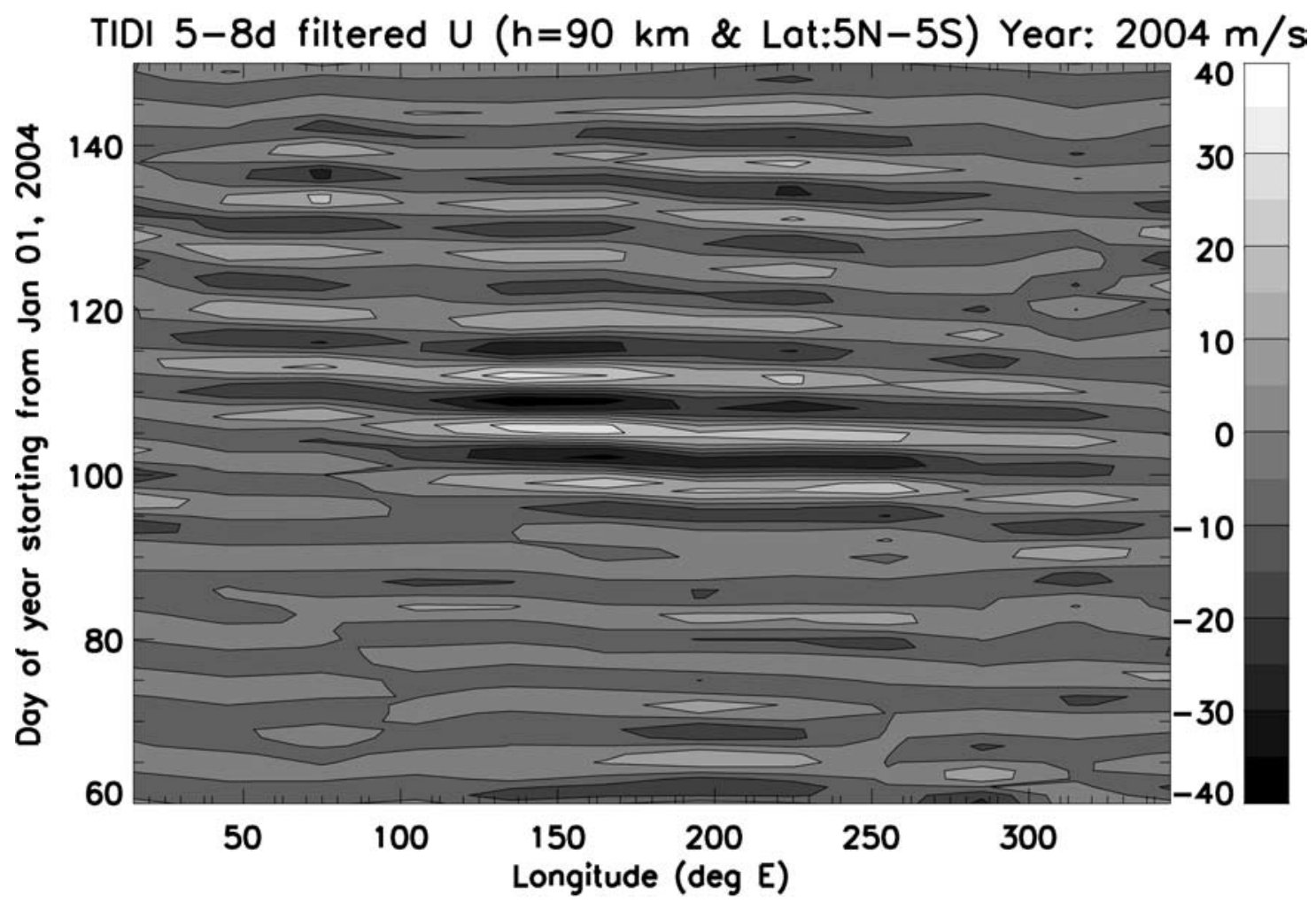

Fig. 1. Longitude-time cross section of 5-8-day filtered winds over the equator for the period of MarchMay 2004.
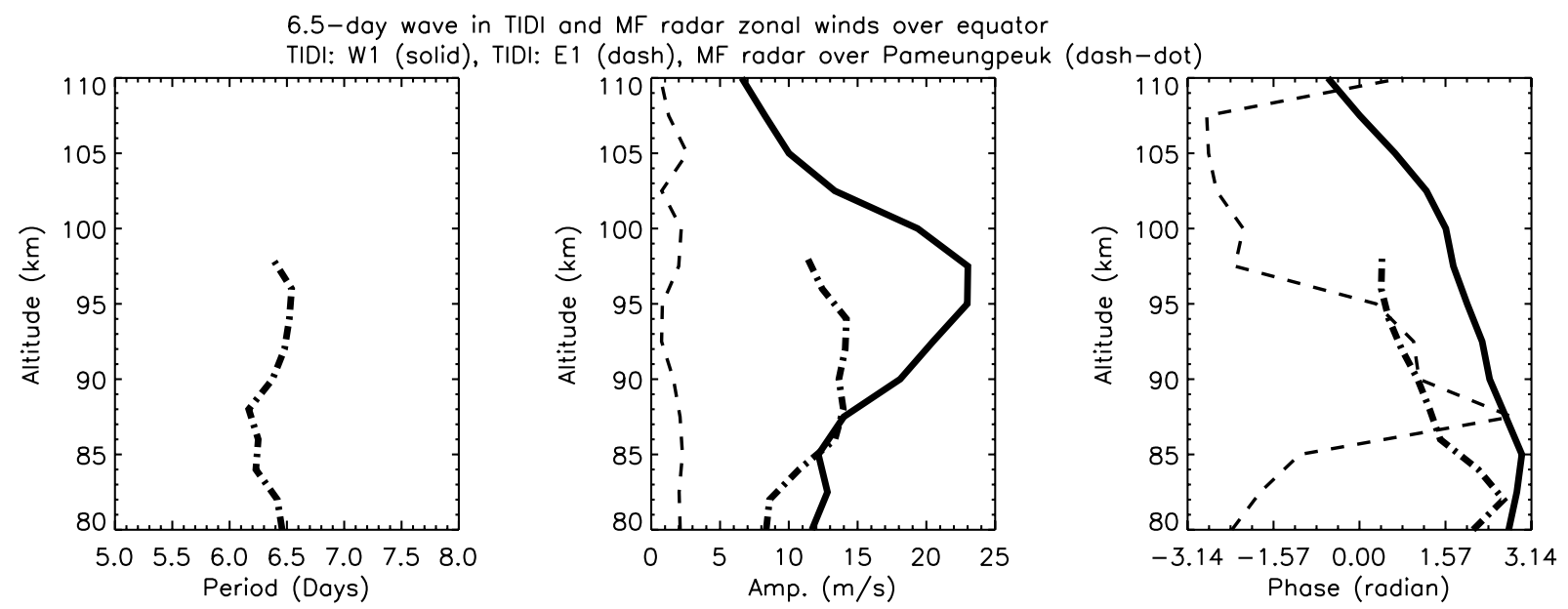

Fig. 2. Altitude profiles of dominant wave period (left panel), 6.5-day amplitude (middle panel), and phase (right panel) in the zonal winds over Pameungpeuk (dash-dot). W1 (solid) and E1 (dashed) components of the 5-8-day wave in TIDI winds are plotted for comparison. 


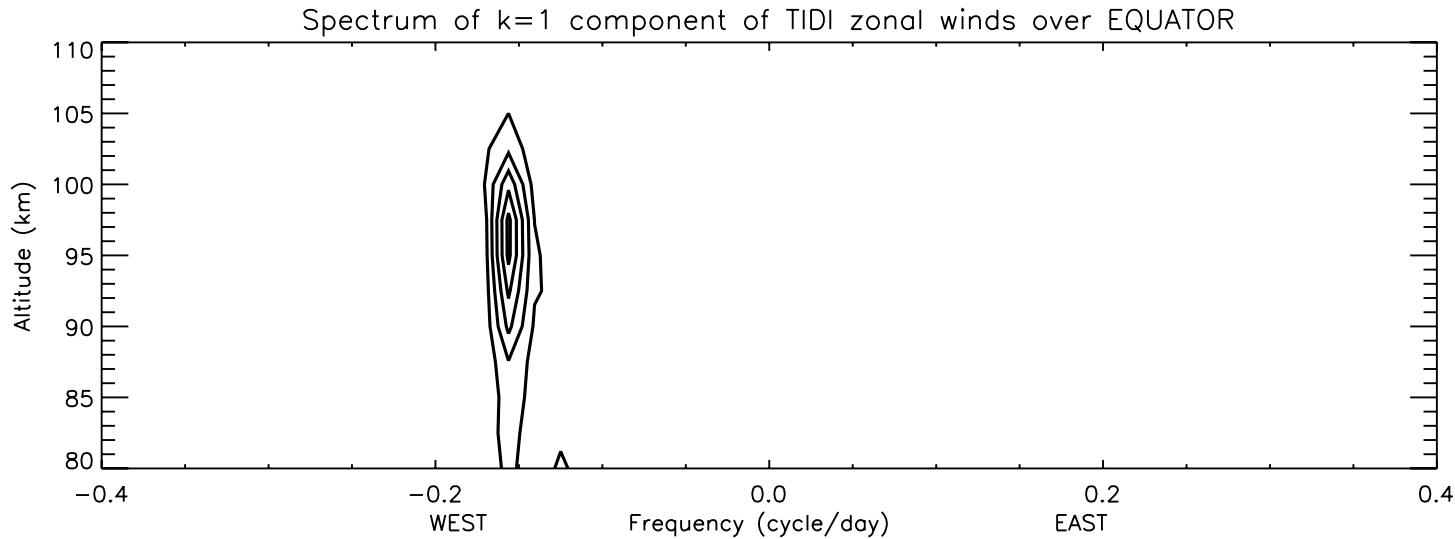

Spectrum of $k=1$ component of ECMWF zonal winds over EQUATOR

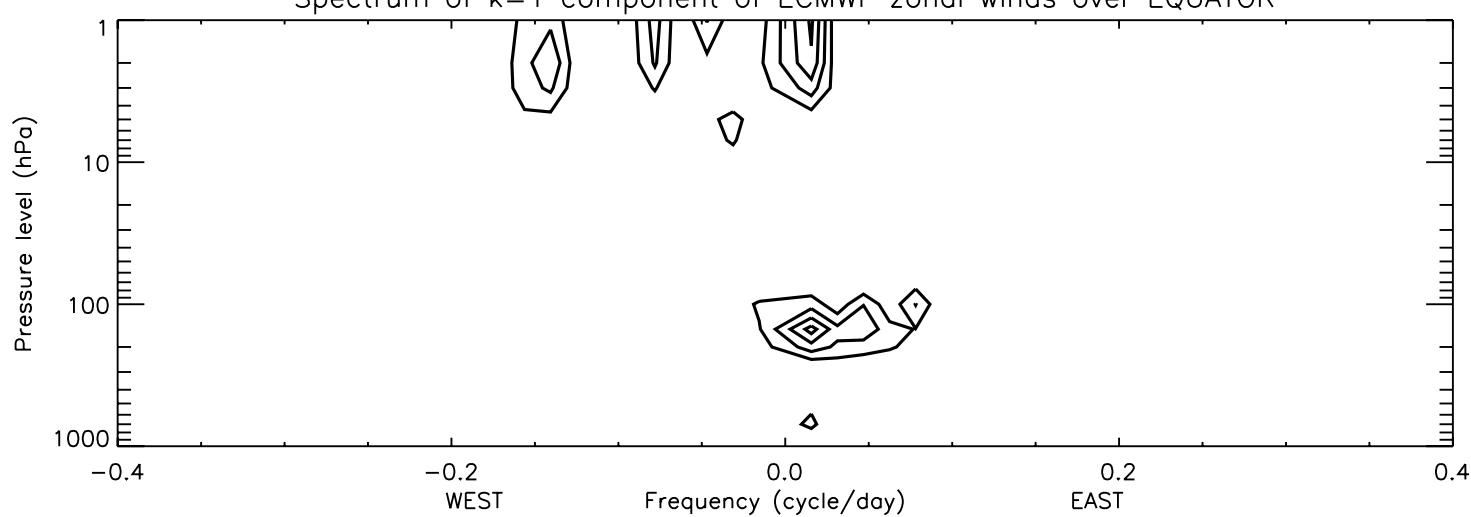

Fig. 3. Spectrum of $\mathrm{k}=1$ component in TIDI winds (top panel) and ECMWF winds (bottom panel) over the equator for the period of March 23-May 26, 2004.

obtained in the MF radar winds is approximately half that obtained in the TIDI winds. The amplitude difference could be due to an instrumental difference and/or a difference in the method of analysis. In the case of the TIDI winds, the amplitude profile is shown for the $\mathrm{W} 1$ component over the equator. However, in case of the MF radar winds, the amplitude profile of the 5-8-day wave, which could be a superposition of different scales, is plotted. Since the time resolution of the MF radar over Pameungpeuk is nearly 1.5 minutes, the daily winds are averaged winds. Thus, the variance in these winds will be smaller than the TIDI winds, which are instantaneous winds derived when the satellite passed over the region.

In the TIDI winds, there is a slight difference in the height of maximum amplitude, which is observed at $97.5 \mathrm{~km}$ in the TIDI winds and at 94 $\mathrm{km}$ in the MF radar winds. The phase structure of the W1 component shows a clear downward phase progression, which indicates upward en- ergy propagation and is consistent with that of the 6.5-day wave in the MF radar winds. The vertical wavelength computed from the variation of phase with height is approximately $50 \mathrm{~km}$. The phase structure of the E1 component has an irregular structure.

\subsection{Spectral analysis of TIDI and ECMWF winds}

As the W1 component shows downward phase propagation to $80 \mathrm{~km}$, it indicates that the wave must be propagating from any altitude below 80 $\mathrm{km}$. We use the ECMWF winds to investigate whether the wave is present in the stratosphere and troposphere by employing a spectral analysis of the ECMWF zonal winds. The bottom panel of Fig. 3 shows the power spectrum of the $k=1$ component ECMWF zonal winds at $1,000-1 \mathrm{hPa}(0$ $-50 \mathrm{~km}$ ). Similar analysis of the TIDI zonal wind data for altitudes from 80 to $110 \mathrm{~km}$ is carried out and the spectrum is plotted in the top panel. In the top panel, peaks are observed only around the 

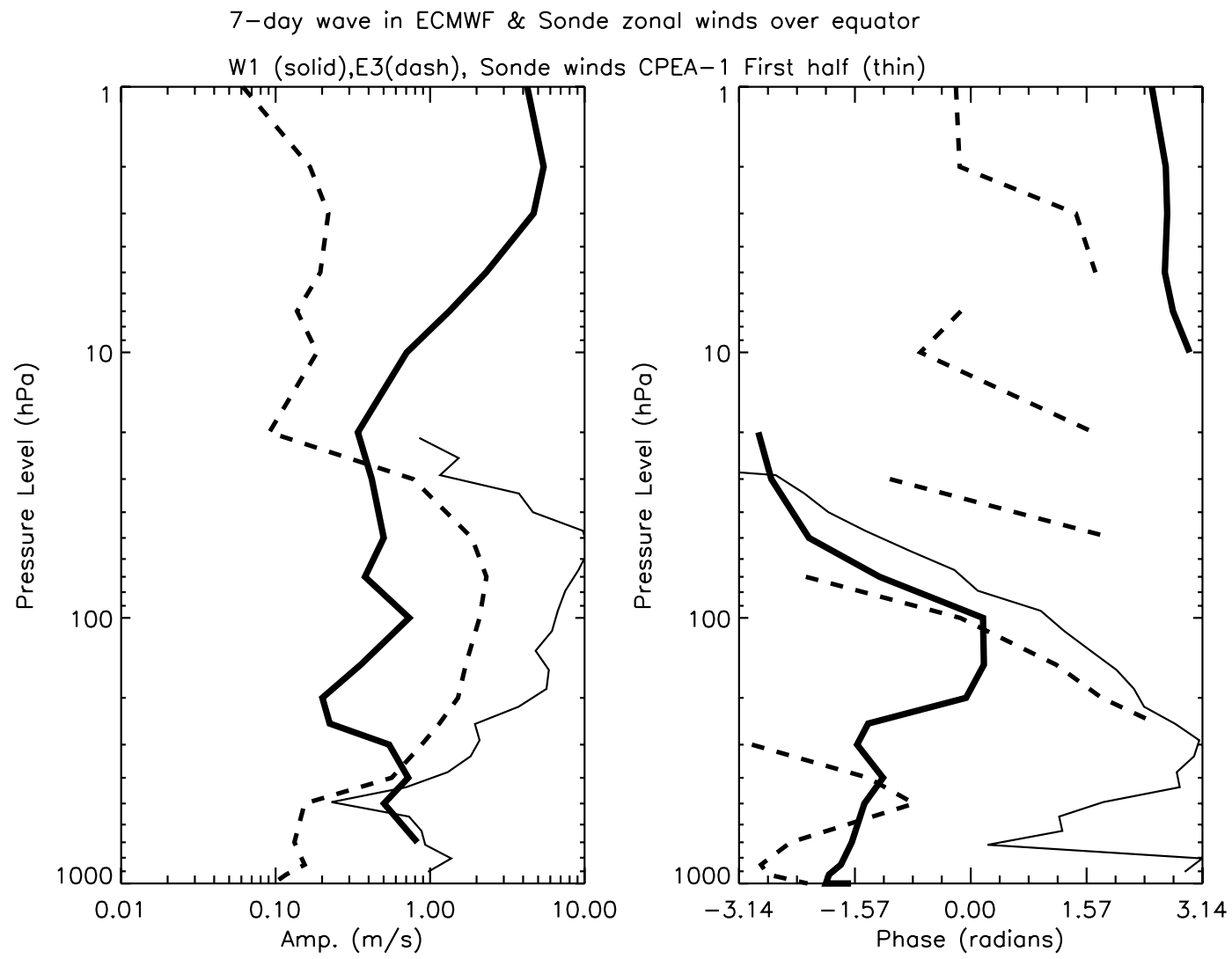

Fig. 4. Altitude profiles, amplitudes, and phases of W1 (solid) and E3 (dashed) components of the 7-day wave in ECMWF winds for the period of March 23-May 26 2004. Seven-day wave amplitude and phase during the first half of CPEA-1 (thin curve) is reproduced from Sridharan et al. (2006a) for comparison. See the text for details.

period of 6.5 days, which shows the dominance of the wave in the MLT region. The peaks extend over all altitudes from 80 to $105 \mathrm{~km}$. The spectral analysis of the ECMWF winds shows the presence of a peak around 7-days at pressure levels above 4 $\mathrm{hPa}$. This indicates the presence of a wave having a period of seven days and with greater energy in the upper stratosphere.

\subsection{Altitude Profiles in the Troposphere and Strato- sphere}

We next examine the altitude profiles of the W1 component in the ECMWF winds in the troposphere and stratosphere. We present the altitude profiles of amplitude and phase of the W1 component (solid curve) in ECMWF winds in Fig. 4. Although the W1 component has smaller amplitude at lower altitudes, it increases rapidly in the upper stratosphere. The upward propagation of the wave can be inferred from the phase profile of the W1 component, which shows downward phase propagation from stratopause to the tropopause. This suggests that the wave might have been generated below the tropopause and propagated upward. In a previous study (Sridharan et al. 2006a), we observed an eastward propagating Kelvin wave having a period of nearly seven days and of zonal wave number 3 in the UTLS region in the radiosonde zonal winds over several sites in South-east Asia. We wish to compare the altitude structure of the wave obtained from the radiosonde winds over one of the sites, Koto Tabang $\left(0.2^{\circ} \mathrm{S}, 100.3^{\circ}\right.$ E) with that from ECMWF winds. Referring to the dotted (ECMWF) and thin (radiosonde) curves in Fig. 4, we infer that the vertical structures of wave amplitude in both winds agree well with each other. In both wind data sets, the largest amplitudes are observed in the lower stratosphere (250-30 

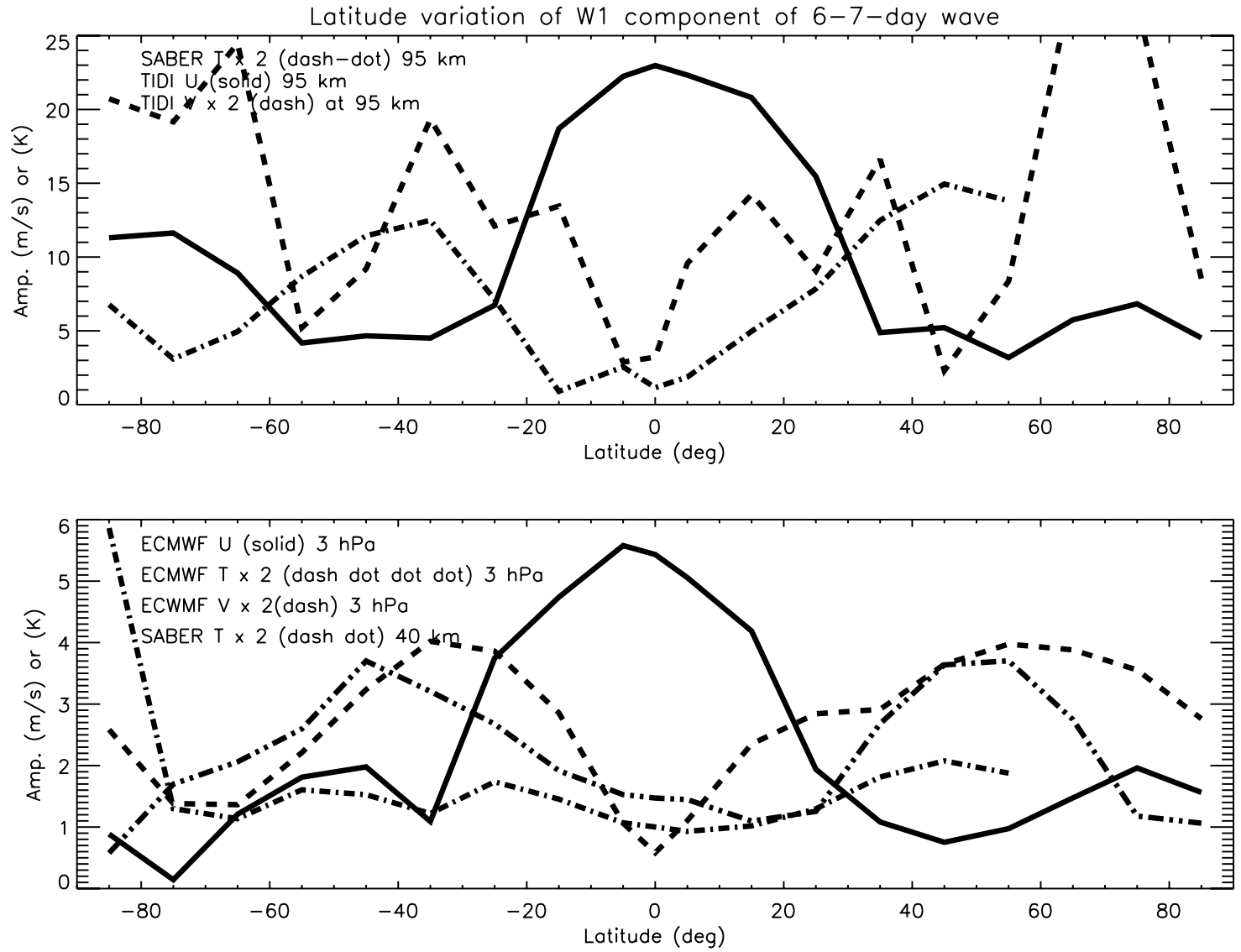

Fig. 5. Latitude variation of the 6.5-day wave in TIDI winds and SABER temperature at $95 \mathrm{~km}$ (top panel). Latitude variations of the 6.5-day wave in ECMW winds and temperature at $3 \mathrm{hPa}$ and of SABER temperature at $40 \mathrm{~km}$ (bottom panel).

$\mathrm{hPa}$. The phase profiles of the E3 component in ECWMF and the radiosonde winds are also consistent with each other, with vertical wavelengths of $5-6 \mathrm{~km}$. The wave becomes damped above 23 $\mathrm{km}(30 \mathrm{hPa})$, and this result is again consistent between the ECMWF and the radiosonde winds. The phase profiles have irregular structures above $30 \mathrm{hPa}$, as the wave amplitudes become smaller. This suggests that the E3 component has been damped and the vertical propagation of the wave is not significant above this level. However, the amplitude of the W1 component begins to increase above this level, and the phase shows downward progression, indicating upward propagation of the wave.

\subsection{Latitude structure}

In order to find the type of waves observed at MLT heights, the amplitude of the W1 component in TIDI zonal and meridional winds and in the SABER temperatures at $95 \mathrm{~km}$ altitude, where the wave has larger amplitude in the zonal wind, is plotted as function of the latitude in the top panel of Fig. 5. Similarly, the latitude variation of the amplitude of the W1 component in the ECMWF zonal and meridional winds, and temperature at $3 \mathrm{hPa}$ and in the SABER temperature at $40 \mathrm{~km}$ is shown in the bottom panel. At both MLT and stratopause heights, the zonal wind amplitudes show a broader peak over the equator and a larger amplitude is observed between $20^{\circ} \mathrm{S}-20^{\circ} \mathrm{N}$. Note that the latitude distribution of the wave is different with respect to zonal wind and temperature. At MLT heights (top panel), the wave amplitude in the SABER temperature shows a larger amplitude $(\sim 7 \mathrm{~K})$ over mid-latitudes $\left(30^{\circ}-60^{\circ}\right)$ than over the equator. The maximum values are observed to occur at $45^{\circ} \mathrm{N}$ and $35^{\circ} \mathrm{S}$. The meridional wind 

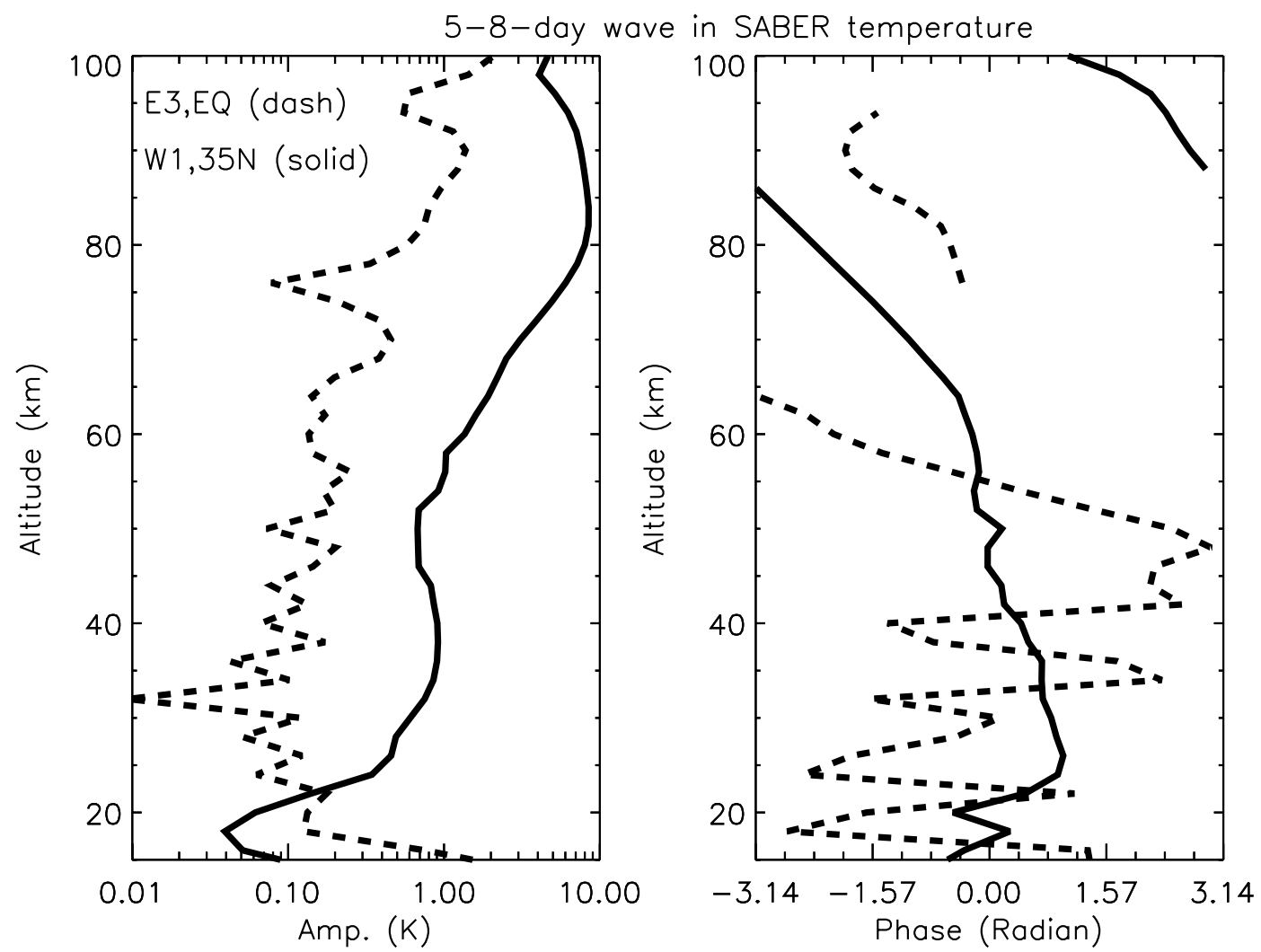

Fig. 6. Amplitude and phase of $\mathrm{W} 1$ and E3 components of the 6.5-day wave over the equator (dashed) and $35 \mathrm{~N}$ (solid) of SABER temperature.

amplitude is nearly zero over the equator and does not vary notably with latitude. In the bottom panel, the temperature amplitude is similar in the ECMWF and the SABER data, with maximum values over mid-latitudes and minimum values over the equator. The latitudinal structures of the wave in temperature and winds observed at MLT and stratopause heights are consistent with the theoretical Rossby wave first symmetric $(1,1)$ mode. We also checked the latitude structure of the wave in the lower stratosphere. Although the amplitude of the wave is smaller, it shows the latitude structure of the Rossby wave symmetric mode, particularly with respect to temperature.

\subsection{Altitude profiles in SABER temperature}

The SABER temperature has the advantage of covering altitudes from nearly $15 \mathrm{~km}$ to $110 \mathrm{~km}$ and so is used to find the altitude variation of the 6.5-day wave from the troposphere to the MLT region. Since the amplitude of W1 component in temperature shows maxima at mid-latitudes, we analyzed the profile at mid-latitudes. The altitude profile of the wave amplitude and the relative phase of the $\mathrm{W} 1$ component at $35^{\circ} \mathrm{N}$ are plotted in Fig. 6 as the solid curve. The amplitude of the W1 component increases with altitude and reaches a maximum of nearly $10 \mathrm{~K}$ at an altitude of 80 $\mathrm{km}$. The maximum value observed here is consistent with the HRDI observations (Talaat et al. 2001). The phase profile also shows downward phase propagation with altitude. At altitudes above $60 \mathrm{~km}$, the vertical wavelength estimated from the phase variation of the wave is approximately 50 $\mathrm{km}$ and is consistent with that estimated from the TIDI and MF radar winds over the equator (Fig. 2 ). Yee et al. (2001) observed a similar vertical wavelength of $50-60 \mathrm{~km}$ for the 6.5-day wave in the HRDI wind observations for the years 1993 -94 . Note that the wave has a longer vertical wavelength $(>100 \mathrm{~km})$ in the stratosphere $(20$ $60 \mathrm{~km}$ ). Talaat et al. (2002) also reported a longer vertical wavelength at stratospheric heights. They believed this to be due to the reflection of time 
having passed from the initial onset of the wave event. In agreement with previous observations (Sridharan et al. 2006a), the E3 component over the equator (shown as the dashed curve) has a larger amplitude in the lower stratosphere.

\subsection{OLR decomposition}

The daily OLR data for the period of MarchMay 2004 for each latitude are separated into symmetric and antisymmetric components, and the symmetric component is subjected to a space-time Fourier transform. The wave variances in the period range 5-8-day are summed up separately for the wave components E1, and E3 and W1, and W3 and are plotted as a function of latitude in Fig. 7. The top (bottom) panel shows the eastward (westward) propagating components. In the eastward propagating side, E3 is dominant with a variance as large as approximately $30 \mathrm{~W}^{2} \mathrm{~m}^{-4}$, whereas in the westward propagating side, W1 is dominant, but much weaker than E3, with a relatively smaller variance of approximately $12 \mathrm{~W}^{2} \mathrm{~m}^{-4}$. This latitude structure shows that the E3 component is dominant over the equator, whereas the $\mathrm{W} 1$ component has a maximum amplitude slightly distant from the equator. In Fig. 3c of Wheeler et al. (2006), the equatorial Rossby wave in OLR has a larger variance slightly distant from the equator $\left( \pm 10^{\circ}\right)$. The presence of waves of similar periodicities and zonal structure at higher altitudes of the atmosphere suggests that these waves might have been generated due to convective heating. After their generation, the oscillation becomes free from convection, propagates upward as waves, and can be observed in the measurements at higher altitudes.

Previous observations of the 6.5-day wave in the MLT region show that the wave is mainly an equinoctial phenomenon (for example, Kovalam et al. 1999; Talaat et al. 2001). In order to determine whether similar periodicity is present during the equinoctial months of other years, the temporal variation of the W1 component of the 5-8-day wave for the years 1993-2006 is shown in Fig. 8. The figure indicates that larger enhancements in the wave variance can be observed from February to April, compared to other months. The wave energy approximately equal to or greater than 30 $\mathrm{W}^{2} \mathrm{~m}^{-4}$ is observed during April in 1993, 1998, and 2001. During 2002-2004, the wave variance ranges from 20 to $30 \mathrm{~W}^{2} \mathrm{~m}^{-4}$. During other years, although the variance of the 5-8-day wave is much

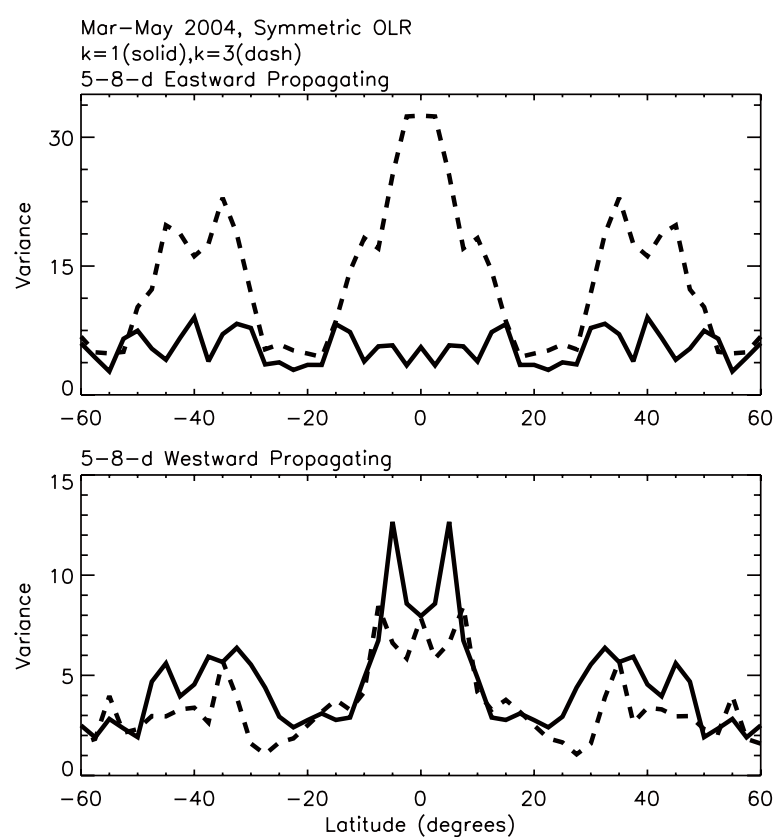

Fig. 7. Latitude variation in variance of $\mathrm{E} 1$ (solid) and E3 (dashed) components of 5 -8-day periodicity in symmetric OLR (top panel). Latitude variation in variance of W1 (solid) and W3 (dashed) components of 5-8-day periodicity in symmetric OLR (bottom panel).

smaller, the maximum/secondary maximum variance in some of the years (1997, 2000 and 2006) occurs from February to April. This indicates that tropical convective heating could be the source for westward propagating 6.5-day Rossby wave events that occur from February to April. However, the vertical propagation of the wave to MLT heights depends on the background wind and temperature conditions through which they propagate.

\section{Discussion and Conclusion}

The horizontal and vertical structures of 58-day waves during the CPEA-I campaign (March -May 2004) have been studied using MF radar, radiosonde, and TIMED satellite measurements of winds and temperatures. In the lower stratosphere (at approximately $20 \mathrm{~km}$ ), the wave having a period close to 7-days and propagating eastward with zonal wave number 3 is dominant. The characteristics of these waves are consistent with those of equatorial Kelvin waves. However, the wave is damped above $23 \mathrm{~km}$. At heights above 23 


\section{W1 component of 5-8-day periodicity in OLR (10N-10S)}

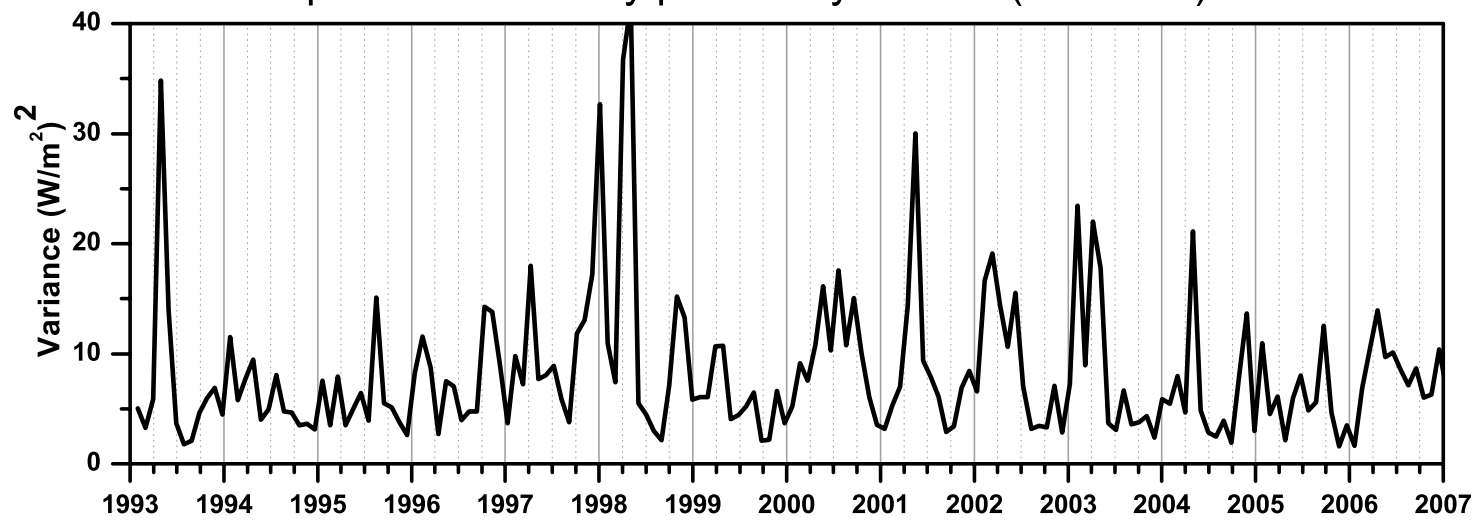

Fig. 8. Temporal variation of the $\mathrm{W} 1$ component of the 5-8-day periodicity in OLR averaged for $10^{\circ} \mathrm{N}-10^{\circ}$ S for the years 1993-2006.

$\mathrm{km}$, a westward propagating wave having a similar periodicity to zonal wave number 1 is dominant in the upper stratosphere, the mesosphere, and the lower thermosphere. This wave shows the characteristics of the symmetric Rossby wave. The amplitude increase and phase decrease with increasing altitude appear to be continuous from the lower stratosphere to MLT heights.

There have been several observations and theoretical studies on planetary scale waves of having periods of between five and eight days in the mesosphere and lower thermosphere $(\mathrm{Wu}$ et al. 1994; Meyer and Forbes 1997; Kovalam et al. 1999; Talaat et al. 2001, 2002; Lieberman et al. 2003; Liu et al. 2004). As in the present study, these waves have, in general, been identified as symmetric Rossby waves. Since they have periods close to 6.5 days, they are commonly referred to as 6.5-day waves. Different sources have been suggested for the generation of these waves. $\mathrm{Wu}$ et al. (1994) identified the wave as a Doppler-shifted 5-day wave of normal mode. However, as the wave shows distinct phase variation with height and the change of the 5-day wave period due to Doppler shift would be less than 0.5 days (Geisler and Dickinson 1979), Meyer and Forbes (1997) proposed that the wave could be generated at middle and high latitudes due to baroclinic/barotropic instabilities, which could act as an in situ wave source for the planetary wave. Lieberman et al. (2003) provided observational support for the wave as an unstable wave and suggested that the wave was amplified by baroclinic instability. Recent model simulations by Liu et al. (2004) have demonstrated the importance of the atmospheric zonal wind in the propagation and amplification or decay of the 6.5-day wave. In particular, the seasonal variability is found to be dependent on the variability of the wave guide, baroclinic/barotropic instability, and the critical layer of the wave. However, Talaat et al. (2001) found little middle or high latitude structure in the zonal wind amplitude in their HRDI observations, which is unexpected if the forcing mechanism is located there. They viewed the 6.5-day wave as an internal Rossby wave propagating from the lower atmosphere, rather than as an external Lamb wave. Using the combination of UKMO stratospheric data and HRDI MLT wind observations, Talaat et al. (2002) found that the amplitude and phase structure of the wave is consistent from the stratosphere to MLT altitudes and suggested that the wave propagated vertically from the stratosphere to the MLT region.

A few modeling studies have suggested possible source mechanisms for the generation of waves having periods of approximately five days. These mechanisms include moist convective tropical heating (Salby and Garica 1987; Garcia and Salby 1987), and topography (Hayashi and Golder 1983). After examining these sources in their GCM experiments, Miyoshi and Hirooka (1999) concluded that the heating process due to moist convection in the troposphere was important for excitation of the 5-day wave. They also indicated that effects of mountains and land-sea contrast on excitation of the 5-day wave were not essential. However, they focused on the 5-day wave of normal mode, which 
has little phase variation with altitude. As reported by Talaat et al. (2001), although the period associated with the resonant equivalent depth for the Rossby $(1,1)$ mode solution is typically five days, the term 5-day wave in the upper atmosphere is a misnomer. Based on past observations, as well as the findings of the present study, the Rossby $(1,1)$ mode in the upper atmosphere is found to occur at periods between six and seven days in the MLT region.

Considering these past observations and theoretical studies, the present study investigates tropical convection as a possible source for the 5 -8-day waves. Latent heat release within organized tropical convection is the principal heating mechanism that generates lower frequency waves, namely, Rossby and Kelvin waves, with periods on the order of a week or more. These waves will be tentatively associated with convection (Takayabu 1994; Hendon and Salby 1994; Wheeler et al. 2000) during the period when they are called convectively coupled waves. Past observations also show that the link between convectively coupled equatorial waves propagated vertically to the stratosphere, as the wave number-frequency scales of the convectively heating variations of these waves is the same as that of some of the waves observed in the stratosphere (e.g., Yanai and Maruyama 1966; Wallace and Kousky 1968; Tsuda et al. 1994; Sato et al. 1994). During the observation period of the present study (March-May 2004), the OLR distribution in the tropics indicated the presence of 7-day periodicity propagating eastward with zonal wave number 3 and westward with zonal wave number 1 . The observation of an eastward propagating 7-day wave with zonal wave number 3 in the lower stratosphere and a westward propagating wave having a period of 6.5 days at higher altitudes and the phase variation with height being nearly continuous and downward from the MLT region to the tropopause suggest that tropical convective heating could be a common source for these Kelvin and Rossby waves.

The dominance of Kelvin wave response in the lower atmosphere can also be explained by the 'mobile wave-CISK mechanism' proposed by Lau and Peng (1987) for the Kelvin wave nature of Madden Julian Oscillation (MJO). They suggested that the eastward propagation of the MJO arises from an intrinsic mode of interaction between convection and Kelvin waves. In this model with positive-only condensational heating, Kelvin waves are selectively amplified. The periodicity of the oscillation is determined by the time required for the moist Kelvin wave to complete one circuit around the globe. However, in his twolevel model study, Hendon (1988) found that the effects of non-linear advection cause the growing CISK modes to rapidly stabilize the atmosphere. The stability increases most toward the west of the CISK heating. It appears that the non-linear advection supported the eastward propagating disturbances with finite wavelengths. Since Kelvin waves become increasingly dominant in the lower atmosphere, the westward propagating Rossby waves are not significant at lower stratospheric heights. Since the QBO in the stratosphere has been in eastward phase during the observation period, the eastward propagating Kelvin wave component might have undergone thermal damping (Sridharan et al. 2006a), while the background wind condition would have been favorable for the westward propagating component to reach MLT altitudes. Finally, as suggested by Talaat et al. (2001), our observations also show that the wave must be forced from the lower atmosphere. Since the proxy for tropical convection (OLR) also shows similar periodicity and zonal scales (W1 and E3), our observations also suggest that these waves could be generated due to tropical convection and propagated upward to the MLT region.

\section{Acknowledgements}

A portion of the present study was completed while one of the authors (S.S.) was working as a Guest Research Associate under the Japanese Society for Promotion of Science (JSPS) program at RISH, Kyoto University, Japan. S.S. wishes to thank Kyoto University and JSPS for providing a fellowship and facilities, which enabled the present study to be conducted. He also would like to thank Department of Space, Government of India for its support to carryout the present study. The present study was supported in part by the grant numbers 13136203 and 19403009 from MEXT, Japan. The TIDI wind (level 2) and SABER temperature data (level 2a, version 1.4) were obtained from the following websites: http://tidi.engin. umichi.edu and http://saber.larc.nasa.gov. The authors would also like to acknowledge Prof. J.M. Russell and Prof. T.L. Killeen, the principal investigators of the SABER and TIDI projects, respectively, and Dr. Q. Wu for discussions regarding the TIDI data sets. The ECMWF ERA-40 data 
used in the present study were obtained from the ECMWF server. Interpolated OLR data were provided by NOAA/OAR/ESRL PSD, Boulder, Colorado, USA through their website at http://www. cdc.noaa.gov. Finally, the authors would like to thank the two anonymous reviewers for their critical evaluation of the manuscript.

\section{References}

Garcia, R.R. and M.L. Salby, 1987: Transient response to localized episodic heating in the tropics, part II, Far-field behaviour. J. Atmos. Sci., 44, 499530.

Geisler, J.E. and R.E. Dickinson, 1976: The five-day wave on a sphere with realistic zonal winds. $J$. Atmos. Sci., 33, 632-641.

Hayashi, Y. and D.G. Golder, 1983: Transient planetary waves simulated by GFDL spectral generation circulation models, part I, Effects of mountains. J. Atmos. Sci., 40, 941-950.

Hagan, M.E., J.M. Forbes, and F. Vial, 1995: On modeling migrating solar tides. Geophys. Res. Lett., 22, 893-896.

Hendon, H.H. and M.L. Salby, 1994: The life cycle of the Madden-Julian oscillation. J. Atmos. Sci., 51, 2225-2237.

Hendon, H.H., 1988: Simple model of the 40-50-day oscillation. J. Atmos. Sci., 45, 569-584.

Killeen, T.M., Q. Wu, S.C. Solomon, D.A. Ortland, W.R. Skinner, R.J. Niciejewski, and D.A. Gell, 2006: TIMED Doppler Interferometer: Overview and Recent Results. J. Geophys. Res., 111, A10201, doi.10.1029/2005JA011484.

Kovalam, S., R.A. Vincent, I.M. Reid, T. Tsuda, T. Nakamura, K. Ohnishi, A. Nuryanto, and W. Wiryosumarto, 1999: Longitudinal variations in planetary wave activity in the equatorial mesosphere. Earth Planets Space, 51, 657-664.

Lau, K.M. and L. Peng, 1987: Origin of low-frequency (intraseasonal) oscillations in the tropical atmosphere, Part I: Basic theory. J. Atmos. Sci., 44, 950-972.

Lieberman R.S., D.M. Riggin, S.J. Franke, A.H. Manson, C. Meek, T. Nakamura, T. Tsuda, R.A. Vincent, and I. Reid, 2003: The 6.5-day wave in the mesosphere and lower thermosphere: Evidence for baroclinic/barotropic instability. J. Geophys. Res., 108(D20), 4640, doi:10.1029/ 2002JD003349.

Liebmann, B. and C.A. Smith, 1996: Description of a complete (interpolated) outgoing longwave radiation dataset. Bull. Amer. Meteor. Soc., 77, 12751277.

Liu, H.-L., E.R. Talaat, R.G. Roble, R.S. Lieberman, D.M. Riggin, and J.-H. Yee. 2004: The 6.5-day wave and its seasonal variability in the middle and upper atmosphere. J. Geophys. Res., 109, D21112, doi:10.1029/2004JD004795.

Longuet-Higgins, M.S., 1968: The eigenfunctions of Laplace's tidal equations over a sphere. Philos. Trans. R. Soc. London, Ser. A, 262, 511-607.

Miyoshi, Y. and T. Hirooka, 1999: A numerical experiment of excitation of the 5-day wave by a GCM. $J$. Atmos. Sci., 56, 1698-1707.

Meyer, C.K. and J.M. Forbes, 1997: A 6.5-day westward propagating planetary wave: Origin and characteristics. J. Geophy. Res., 102, 2617326178.

Ramsberg, E., G. Lingenfelser, V.L. Harvey, W. Grose, J. Russell III, M. Mlynczak, L. Gordley, and B.T. Marshall, 2003: On the verification of the quality of SABER temperature, geopotential height, and wind fields by comparison with Met Office assimilated analyses. J. Geophys. Res., 108(D20), 5628, doi: 10.1029/2003JD003720.

Salby, M.L. and R.R. Garcia, 1987: Transient response to localized episodic heating in the tropics, part I, simple fields. J. Atmos. Sci., 44, 458-498.

Sato, W., M.F. Hasegawa, and I. Hirota, 1994: Shortperiod disturbances in the equatorial lower stratosphere. J. Meteor. Soc. Japan, 72, 859-872.

Sridharan, S., T. Tsuda, R.A. Vincent, T. Nakamura, and Effendy, 2006b: A report on radar observations of 5-8-day waves in the equatorial MLT region. J. Meteor. Soc. Japan, 4, 295-304.

Sridharan, S., T. Tsuda, T. Nakamura, T. Kozu, S. Mori, and J.M. Russell, 2006a Observations of 7-day Kelvin wave in the tropical atmosphere during the CPEA campaign. J. Meteor. Soc. Japan, 84A, 259-275.

Takayabu, Y.N., 1994: Large-scale cloud disturbances associated with equatorial waves. Part I: Special features of the cloud disturbances. J. Meteor. Soc. Japan, 72, 433-448.

Talaat, E.R., J.-H. Yee, and X. Zhu, 2001: Observations of the 6.5-day wave in the mesosphere and lower thermosphere. J. Geophys. Res., 106, 20715 -20723 .

Talaat, E.R., J.-H. Yee, and X. Zhu, 2002: The 6.5-day wave in the tropical stratosphere and mesosphere. J. Geophys. Res., 107(D12), 4133, doi: 10.1029/2001JD000822.

Tsuda, T., Y. Maruyama, H. Wiryosumarto, S.-W.B. Harijono, and S. Kato, 1994: Radiosonde observations of equatorial atmospheric dynamics over Indonesia. J. Geophys. Res., 99, 10491-10505.

Wallace, J.M. and W.E. Kousky, 1968: Observational evidence of Kelvin waves in the tropical stratosphere. J. Atmos. Sci., 25, 900-907.

Wheeler, M., G.N. Kiladis, and P.J. Webster, 2000: Large-scale dynamical fields associated with convectively coupled equatorial waves. J. Atmos. 
Sci., 57, 613-639.

Wu, D.L., P.B. Hays, and W.R. Skinner, 1994: Observations of the 5-day wave in the mesosphere and lower thermosphere. Geophys. Res. Lett., 21, 2733-2736.

Yanai, M. and T. Maruyama, 1966: Stratospheric wave disturbances propagating over the equatorial Pacific. J. Meteor. Soc. Japan, 44, 291-294.

Yee, J.-H, E.R. Talaat, and X. Zhu, 2001: 6.5 day planetary waves in the mesosphere and lower thermosphere. Adv. Space Res., 27, 1761-1765. 